\title{
COMPOSIÇÃO gUIMICA DE TABLETES DE CALDO DE CARNE: NITROGÊNIO PROTÉICO, NÃO-PROTÉICO E FENILALANINA ${ }^{1}$
}

\author{
Claudia Passos GUIMARÃES², Ursula M. LANFER MARQUEZ ${ }^{2, *}$
}

\section{RESUMO}

A redução dos níveis sangüineos de fenilalanina (Phe) em pacientes fenilcetonúricos requer o conhecimento preciso do teor de Phe nos alimentos, para que possa haver um controle da ingestão desse aminoácido. Este trabalho teve como objetivo estudar o teor protéico e de Phe em tabletes de caldo de carne de duas marcas comerciais, contribuindo com informações para a elaboração de cardápios. A análise de aminoácidos foi realizada por cromatografia de troca iônica em autoanalisador de aminoácidos e os teores de umidade, proteína bruta $(\mathrm{Nx6}, 25)$ e lipídeos foram determinados por métodos descritos na AOAC (1995). A fibra alimentar foi quantificada por método enzimático. O nitrogênio protéico (NP) foi determinado após precipitação ácida da proteína. Observamos que os teores de umidade, lipídeos foram semelhantes nos dois produtos com valores médios de 3,7\%, e 8,4\%, respectivamente. Os teores de fibra foram inferiores a $2 \%$, mas vale ressaltar o elevado teor de minerais, da ordem de $61 \%$ no produto A e de $54 \%$ no produto B. Comparando-se os valores de nitrogênio total e NP, verificamos que aproximadamente $95 \%$ do $\mathrm{N}$ correspondem a $\mathrm{N}$ de origem não protéica. O teor protéico real, pela somatória de aminoácidos, era de apenas $0,71 \mathrm{~g} / 100 \mathrm{~g}$ e de $0,84 \mathrm{~g} / 100 \mathrm{~g}$ nas amostras $\mathrm{A}$ e $\mathrm{B}$, respectivamente, e não foi possivel detectar a presença de Phe nestas amostras. Teoricamente, considerando que uma proteina contém $4 \%$ de Phe em sua composição, as amostras analisadas contém no máximo 34mg Phe/100g, o que corresponde a 3,6mg Phe por tablete de caldo de carne de 10,5g. Esta reduzida quantidade justifica a dificuldade em se detectar analiticamente este aminoácido. A elevada quantidade de nitrogênio não protéico corresponde à presença de monoglutamato de sódio (realçador de sabor), de modo que a conversão Nx6,25 resulta em valores protéicos superestimados.

Palavras-chave: fenilalanina; tabletes de caldo de carne; fenilcetonúria; tratamento.

\section{SUMMARY}

CHEMICAL COMPOSITION OF BOUILLON CUBES PROTEIN NITROGEN, NON PROTEIN NITROGEN AND PHENYLALANINE. The dietary intervention to lower the phenylalanine (Phe) serum levels of patients with Phenylketonuria (PKU) requires a restricted supply and the precise knowledge of Phe contents in foods, in order to control the intake of this amino acid. This work aimed to get more accurate data for protein and Phe contents in soup cubes of two commercial products to give dieticians data they need for planning diets. The amino acid contents were estimated by ion-exchange chromatography and moisture, lipids, crude protein (Nx6.25) contents were determined according to AOAC (1995) methods. Fiber was determined enzymatically. Protein nitrogen was determined after acid precipitation. Our results showed in both products, similar moisture and lipid contents with mean values of 3.7 and $8.4 \%$, respectively. Dietary fiber contents were lower than $2 \%$ but it is worthy to mention the high mineral contents $61 \%$ in product A and $54 \%$ in product B. The comparison of total nitrogen (TN) and protein nitrogen (PN), shows that approximately $95 \%$ of TN corresponds to $\mathrm{N}$ of non protein origin. The real protein contents were only $0.71 \mathrm{~g} / 100 \mathrm{~g}$ and $0.84 \mathrm{~g} / 100 \mathrm{~g}$ in samples A and B, respectively and we were not able to detect phenylalanine. Theoretically, based solely on calculations and considering that proteins contain about $4 \%$ Phe in their constitution, the samples contain a maximum of $34 \mathrm{mg}$ Phe $/ 100 \mathrm{~g}$, meaning $3.6 \mathrm{mg}$ Phe per each cube of $10.5 \mathrm{~g}$. These small amounts of Phe could explain the enormous difficulty in detecting this amino acid. The high amount of non-protein $\mathrm{N}$ is due to the presence of monosodium glutamate, which does not allow a reliable protein estimation by Nx6.25, resulting in protein and Phe overestimation.

Keywords: phenylalanine; soup cubes; phenylketonuria; dietary treatment.

\section{1 - INTRODUÇÃO}

A fenilcetonúria é uma doença hereditária do metabolismo da Phe, que resulta em graves alterações no desenvolvimento orgânico e mental se não for diagnosticada precocemente e tratada através de uma dieta com quantidade controlada de Phe [1].

Uma vez diagnosticada, o tratamento dietário desta anomalia consiste na administração de uma dieta restrita em Phe, atendendo à necessidade de manter a concentração sangüinea de Phe em niveis semelhantes aos de uma pessoa saudável. A intenção da dieta é a de fornecer ao organismo apenas a quantidade de Phe imprescindivel para a sintese e regeneração de proteinas, para garantir

Recebido para publicação em 15/08/2001. Aceito para publicação em 05/03/2002

Departamento de Alimentos e Nutrição Experimental. Faculdade de Ciências Farmacêuticas/USP. Av. Prof. Lineu Prestes, 580. CEP 05508900, tel: (011) 38183712. São Paulo, SP. BR. E-mail: lanferum@usp.br. * A quem a correspondência deve ser enviada. um desenvolvimento normal da criança. Os requerimentos dos demais nutrientes seguem os padrões para indivíduos normais, estabelecidos para cada faixa etária pela FAO/WHO [10] e representam a base para o cálculo e formulação da dieta dos pacientes fenilcetonúricos. A manutenção desta dieta especial, mesmo durante a vida adulta, é sugerida por diversos pesquisadores, e tem sido assunto de intensos debates na literatura [8, 11, 13, 19, 24 , 33]. Mas, atualmente, recomenda-se a continuidade do tratamento pela vida inteira, conforme documento elaborado por especialistas, baseado exclusivamente em evidências cientificas, publicado em outubro de 2000 pelo NIH (National Institute of Health) [26].

A formulação de cardápios para pacientes fenilcetonúricos requer o conhecimento preciso do teor de Phe contido nos alimentos, para que possa haver um controle da ingestão desse aminoácido, e embora pareça ser uma tarefa fácil, as dificuldades em compor o cardápio para estes pacientes são grandes. Diversas causas podem ser apontadas: primeiramente o reduzido núme- 
ro de alimentos com baixo conteúdo protéico, a falta de alimentos industrializados especiais formulados especialmente para esta parcela da população, bem como o desconhecimento dos teores de Phe na grande maioria dos alimentos comercializados no pais.

Enquanto nos EUA e na Europa já existem informações sobre a composição de alimentos destinados aos fenilcetonúricos contendo principalmente dados sobre alimentos industrializados, a preocupação, aqui no Brasil, com esta parcela da população, e o interesse na fabricação de alimentos especiais é apenas incipiente [7, 28, 31]. Além disso, os dados publicados no exterior, infelizmente não podem ser utilizados aqui, por corresponderem a alimentos inexistentes no comércio nacional, ou por serem valores desatualizados obtidos por metodologias inadequadas.

Muitos alimentos com reduzido teor protéico não foram analisados com relação ao seu conteúdo em Phe, pois não são fontes de proteína, havendo pouco interesse no conhecimento do seu perfil de aminoácidos. Ademais, o custo da análise de aminoácidos é elevado e existe uma grande dificuldade em quantificar este aminoácido em alimentos de composição complexa. A análise do teor de Phe por um método específico e direto como a análise de aminoácidos é dispendiosa e exige o uso de equipamento analitico sofisticado. Assim, a composição em aminoácidos é estabelecida, na maioria das vezes, apenas nos alimentos considerados fontes protéicas, quando se procura avaliar o valor nutricional da proteína a partir do seu perfil de aminoácidos [20].

Em alimentos com reduzido teor protéico costumase estimar o teor de Phe por cálculo, a partir da análise do teor de nitrogênio total [7, 20]. O método de Kjeldahl [3] é o mais utilizado mundialmente, convertendo-se o N quantificado para proteina, por um fator de conversão (geralmente 6,25). Métodos tais como o de NOLL [25], LOWRY et al. [22], BRADFORD [6], e etc., são pouco utilizados para esta finalidade, sendo os dois últimos mais apropriados para proteínas em solução.

Considerando que a maioria das proteínas possui entre 3-5\% de fenilalanina em sua composição é possível estimar com certa precisão a quantidade de Phe a partir do teor protéico, desde que o fator de conversão $\mathrm{N}: \mathrm{P}$ seja correto [2]. Este fator foi estabelecido por JONES [18] já em 1931, para proteínas da carne, que contêm $16 \%$ de nitrogênio na sua constituição e uma quantidade reduzida de nitrogênio não-protéico. Assim, o uso do fator 6,25 pressupõe que a proteina contenha $16 \%$ de $\mathrm{N}$ e uma quantidade desprezivel de $\mathrm{N}$ não protéico. A presença de substâncias nitrogenadas não protéicas, tais como aminoácidos livres, quitina, ácidos nucléicos e sais inorgânicos como, $\mathrm{NO}_{3}^{-}, \mathrm{NO}_{2}^{-}, \mathrm{NH}_{3}, \mathrm{NH}_{4}^{+}$, superestimam o teor protéico, e, portanto, a concentração de Phe [16, 23, 27, 29, 30, 32, 34]. Em função do perfil de aminoácidos e da presença de compostos nitrogenados não protéicos, outros fatores de conversão mais adequados, devem ser estabelecidos [9, 14, 21, 34].

O propósito deste trabalho foi estudar a composição química, a fração nitrogenada, protéica e não-protéica, com ênfase na determinação do teor de Phe, em "tabletes de caldo de carne" de duas marcas comerciais.

A presença de monoglutamato de sódio nestas amostras de caldo de carne, como realçadores de sabor, resulta em elevado teor de nitrogênio total, embora não contribua com Phe, de modo que tanto a conversão do nitrogênio total para proteína, quanto a estimativa do teor de Phe certamente se encontram superestimados.

Este estudo se justifica pelo fato destes caldos de carne serem ingredientes úteis para conferir sabor aos pratos insossos, geralmente preparados à base de amido e vegetais que compõem o cardápio diário dos pacientes fenilcetonúricos e, provavelmente, por conterem um teor protéico reduzido.

\section{2 - MATERIAL E MÉTODOS}

\section{1 - Amostras}

Os preparados para caldo de carne de duas marcas comerciais "A" e "B", comercializados em uma primeira embalagem de papel laminado e uma segunda embalagem de papelão, contendo 6 tabletes, peso líquido médio de $60 \mathrm{~g}$, validade de 2 anos a partir da data de fabricação, foram adquiridos no comércio local da Cidade de São Paulo, SP, e armazenados em local fresco até o momento da análise.

\section{2 - Análises químicas}

A porcentagem de umidade e a concentração de cinzas foram determinadas de acordo com o método gravimétrico descrito pelo INSTITUTO ADOLFO LUTZ [17], por secagem em estufa a $105^{\circ} \mathrm{C}$ durante 4 horas, na presença de areia, para umidade, e combustão em mufla a $550^{\circ} \mathrm{C}$, por 8 horas.

O teor de proteína bruta foi determinado pelo método semi-micro de Kjeldahl [3], convertendo-se o teor total de $\mathrm{N}$ em proteína pelo uso do fator 6,25. O teor de lipídeos foi determinado pela extração com metanol e clorofórmio, de acordo com o método descrito por FOLCH, LEE \& SLOANNE [12].

O teor de nitrogênio de origem protéica foi determinado pela precipitação da proteína com ácido acético 5,0\% [15] ou ácido tricloroacético (TCA) a 12,5\%. O precipitado resultante foi analisado quanto ao teor de $\mathrm{N}$ pelo método semi-micro Kjeldah1 [3], que então foi convertido para proteína por multiplicação por 6,25.

O teor de fibra alimentar total foi determinado por método enzimático, segundo AOAC [3].

A análise de aminoácidos foi realizada com amostras previamente desengorduradas de acordo com o método mencionado anteriormente, embora o objetivo nesta fase foi apenas desengordurar as amostras, uma vez que a presença de gordura interfere na análise de aminoácidos.

As amostras, contendo aproximadamente $5 \mathrm{mg}$ de proteina, foram hidrolisadas em ampolas seladas a 
vácuo,contendo $1 \mathrm{~mL}$ de $\mathrm{HCl} 6 \mathrm{~N}$ e norleucina como padrão interno. As ampolas foram mantidas em estufa a $110^{\circ} \mathrm{C}$, por 22 horas. Decorrido este tempo, o ácido clorídrico foi removido, colocando as ampolas abertas em dessecador a vácuo, na presença de pastilhas de $\mathrm{NaOH}$. Os resíduos foram ressuspensos em $10 \mu \mathrm{L}$ de tampão citrato, pH 2,2 (Na-S, Beckman Instr. Inc., Palo Alto, CA) e filtrados em membrana de 0,22m (Millipore GSWPO 1300). Estas amostras foram guardadas em frascos herméticos, em geladeira, até o momento da análise. A análise foi realizada por cromatografia de troca iônica e reação dos aminoácidos com ninidrina, pós-coluna [5] em autoanalisador de aminoácidos Beckman modelo 7300, acoplado a uma interface analógica Beckman, modelo 406, (Goldsystem). O equipamento é equipado com coluna de $200 \mathrm{~mm}$ de comprimento contendo resina de troca iônica de sódio e operando em condições para hidrolisados protéicos, definidas pelo fabricante.

Todas as análises químicas foram realizadas em triplicata a partir de diferentes lotes e os resultados expressos como média dos valores, acompanhados dos desvios padrão.

\section{3 - RESULTADOS E DISCUSSÃO}

A composição química dos tabletes de caldo de carne está apresentada na Tabela 1. As duas amostras analisadas apresentam um conteúdo de umidade baixo, situando-se entre 3,0 e 4,3\% nas amostras A e B, respectivamente. A concentração de fibras alimentares foi de $1,86 \%$ na amostra $\mathrm{A}$ e $0,70 \%$ na amostra $\mathrm{B}$. Os teores lipídicos foram elevados, semelhantes para as duas marcas, da ordem de $17 \%$. A concentração de minerais foi elevada: 61,25 e 54,14\% nas amostras A e B, respectivamente. $\mathrm{O}$ alto teor de minerais pode ser justificado pelo fato dos tabletes de caldo de carne conterem elevada concentração de sal, temperos e realçadores de sabor, sendo empregados para conferir sabor a molhos, carnes, arroz, legumes e outros alimentos.

Verificamos que os teores de $\mathrm{N}$ total foram de 1,37\% e 1,31\% nas amostras A e B, respectivamente, enquanto que o teor de $\mathrm{N}$ protéico, isto é, após precipitação da proteína em meio ácido, foi de apenas 0,07\% e 0,08\% nas amostras A e B, respectivamente.

Comparando os valores de $\mathrm{N}$ total e de $\mathrm{N}$ protéico, verificamos que aproximadamente $95 \%$ do $\mathrm{N}$ total correspondem a $\mathrm{N}$ de origem não protéica. Estes resultados confirmam que a utilização do fator de conversão 6,25 multiplicado pelo teor de nitrogênio não é adequada para estimar o teor protéico e conseqüentemente a quantidade de Phe neste tipo de alimento. A análise do teor de N, pelo método de Kjeldahl, foi realizada tanto nas amostras integrais como nas amostras desengorduradas e foi observado que a presença da gordura não interferiu nos teores de nitrogênio recuperados.

O N total convertido para proteina pela multiplicação por 6,25, resultou em teores protéicos brutos de 8,57 e $8,20 \%$ nas amostras A e B, respectivamente. Um produto, aparentemente similar ao analisado por nós, pro- duzido e comercializado na Alemanha possui, de acordo com o fabricante, $21,2 \%$ de proteina bruta e $25 \%$ de lipídeos, conforme publicação em tabela de composição de alimentos destinada a pacientes com desordens no metabolismo de aminoácidos [4]. Da mesma forma, a composição de "Tabletes de caldo de carne" constante na recém-editada $\sigma^{a}$ edição da Tabela Alemã de Composição de Alimentos [31], reporta uma concentração protéica média de $15,80 \%$ para tabletes de caldo de carne. Outros pesquisadores encontraram um teor de aminoácidos totais de 14,83g/100g de "Extrato de carne granulado", e uma participação de $460 \mathrm{mg}$ de Phe/100g de produto [7]. Todos estes valores diferem bastante dos valores por nós encontrados e confirmam a suposição de que alimentos similares ou com denominações parecidas produzidos no exterior podem apresentar diferenças significativas na composição.

TABELA 1. Principais constituintes de duas amostras comerciais de tabletes de caldo de carne.

\begin{tabular}{lrr}
\hline Constituintes $(\mathrm{g} / 100 \mathrm{~g})$ & \multicolumn{1}{c}{ Amostras } & \multicolumn{1}{c}{$\mathrm{B}$} \\
\hline Umidade & $2,97 \pm 0,11$ & $4,30 \pm 0,02$ \\
Lipídeos & $17,60 \pm 1,73$ & $16,61 \pm 1,62$ \\
Proteína bruta (Nx6,25) & $8,57 \pm 0,06$ & $8,20 \pm 0,12$ \\
Resíduo Mineral & $61,25 \pm 0,31$ & $54,14 \pm 0,07$ \\
Fibra Alimentar & $1,86 \pm 0,10$ & $0,70 \pm 0,21$ \\
Nitrogênio Total & $1,37 \pm 0,01$ & $1,31 \pm 0,02$ \\
Nitrogênio Protéico & $0,07 \pm 0,00$ & $0,08 \pm 0,00$ \\
Monoglutamato de Sódio & $15,74 \pm 0,26$ & $10,72 \pm 0,65$ \\
Teor protéico & $0,44 \pm 0,00$ & $0,52 \pm 0,01$ \\
(precipitação com ácido acético 5,0\%) & & \\
Teor protéico & $0,71 \pm 0,06$ & $0,84 \pm 0,02$ \\
$(\Sigma$ dos aminoácidos protéicos) & & \\
\hline
\end{tabular}

Foi determinado o teor de nitrogênio de origem exclusivamente protéica, para que pudesse ser estimado o teor de Phe a partir do teor protéico. Precipitou-se a proteína em meio ácido e analisou-se o teor de $\mathrm{N}$ contido no resíduo pelo método de Kjeldahl [3]. Foram testadas três concentrações de cada um dos ácidos para a precipitação: 5,0\%, 10,0\% e 12,5\% de ácido tricloroacético e 0,5\%, $1,0 \%$ e 5,0\% de ácido acético. As recuperações de proteínas mais altas foram observadas com ácido acético 5,0\% e com ácido tricloroacético $12,5 \%$, com valores muito similares entre si, indicando que estes dois procedimentos podem ser empregados indistintamente para precipitar a proteína.

Em ambos os casos, o teor de proteina precipitada e analisada pelo Método de Kjeldahl [3] foi muito baixo, da ordem de 0,44 e 0,52g/100g nas amostras A e B, respectivamente. A determinação de proteínas pelo $\mathrm{N}$ x 6,25 depende de duas condições: a) que o nitrogênio presente esteja inserido em proteínas e b) que $16 \%$ do peso molecular das proteínas corresponda ao nitrogênio. Neste caso, a precisão na análise do teor protéico depende basicamente da exatidão da análise do nitrogênio.

Valores igualmente baixos foram obtidos, somandose a quantidade de cada um dos aminoácidos recupera- 
dos no autoanalisador de aminoácidos: 0,71g/100g para a amostra A e 0,84g/100g para a amostra B. A diferença entre os valores obtidos pela análise do $\mathrm{N}$ pelo Método de Kjeldah1 [3] e pela somatória dos aminoácidos (Tabela 2), pode ser atribuída à dificuldade na recuperação de baixas quantidades de proteina após precipitação e pela imprecisão do método de Kjeldahl.

TABELA 2. Comparação entre a recuperação protéica pelo método de Kjeldahl e pela somatória dos aminoácidos.

\begin{tabular}{lcc}
\hline & \multicolumn{2}{c}{ Proteína (g/100g amostra) } \\
\cline { 2 - 3 } & \multicolumn{1}{c}{$\mathrm{A}$} & $\mathrm{B}$ \\
\hline Método de Kjeldahl & $0,44 \pm 0,01$ & $0,52 \pm 0,01$ \\
Análise de aminoácidos & $0,71 \pm 0,06$ & $0,84 \pm 0,02$ \\
\hline \hline
\end{tabular}

A análise de aminoácidos confirmou os resultados da análise de $\mathrm{N}$ antes e após a precipitação da proteína presente, que grande parte do $\mathrm{N}$ total corresponde ao monoglutamato de sódio. Este aminoácido foi identificado e quantificado como ácido glutâmico, tendo sido o resultado recalculado para o sal sódico. O monoglutamato de sódio cuja presença na formulação dos caldos de carne é permitida pela Legislação Brasileira em vigor (Resolução RDC no 01, de 01/2001), correspondeu a 15,74\% e $10,72 \%$ em peso, das amostras A e B, respectivamente.

$\mathrm{Na}$ Tabela 3 apresentamos os resultados analiticos referentes ao ácido glutâmico analisado antes e após a hidrólise ácida da amostra, o que permitiu diferenciar o ácido glutâmico proveniente do monoglutamato de sódio e da proteína. Verificamos que o ácido glutâmico de origem protéica é insignificante, correspondendo a menos do que $2 \%$ do ácido glutâmico total encontrado.

TABELA 3. Teores de ácido glutâmico e monoglutamato de sódio em duas marcas de tabletes de caldo de carne (g/100g de amostra).

\begin{tabular}{|c|c|c|}
\hline \multirow{2}{*}{ Constituintes } & \multicolumn{2}{|c|}{ Amostras } \\
\hline & $\mathrm{A}$ & $B$ \\
\hline Monoglutamato de sódio(1) & $15,74 \pm 0,26$ & $10,72 \pm 0,65$ \\
\hline Ácido glutâmico total (AGT) & $13,93 \pm 0,02$ & $9,49 \pm 0,57$ \\
\hline Ácido glutâmico protéico (AGP) ${ }^{(3)}$ & $0,20 \pm 0,02$ & $0,16 \pm 0,01$ \\
\hline $\begin{array}{l}\text { Ácido glutâmico proveniente de MGS } \\
\text { (AGT-AGP) }\end{array}$ & $13,73 \pm 0,02$ & $9,33 \pm 0,7$ \\
\hline
\end{tabular}

(1) Ácido Glutâmico recalculado para Monoglutamato de Sódio (MGS) (3) Ácido Glutâmico proveniente de Monoglutamato de Sódio

Um aminograma representativo da amostra desengordurada das duas marcas comerciais estudadas pode ser observado na Figura 1. Esta figura oferece uma idéia realista da proporção entre o ácido glutâmico proveniente do monoglutamato de sódio e o teor dos demais aminoácidos encontrados. Na Tabela 4 são apresentadas as quantidades de cada aminoácido encontrado nas amostras A e B, expressas em mg/100g de amostra, bem como em mg por tablete. As amostras A e B apresentam, respectivamente, $89 \mathrm{mg}$ e $105 \mathrm{mg}$ de aminoácidos protéicos por tablete de caldo de carne $(10,5 \mathrm{~g})$. Com exceção do ácido glutâmico, todos os demais aminoácidos estão presentes em quantidades muito reduzidas, sendo eles: ácido aspártico, treonina, serina, glicina, alanina, valina, isoleucina, leucina, histidina e lisina. Não foi possivel detectar a presença de Phe nas amostras estudadas. Teoricamente, considerando que uma proteína contém $4 \%$ de Phe, as amostras contendo $0,84 \%$ de proteina, possuem no máximo $34 \mathrm{mg}$ de Phe/100g de amostra, o que corresponde a $3,6 \mathrm{mg}$ de $\mathrm{Phe} /$ tablete de caldo de carne $(10,5 \mathrm{~g})$. Esta reduzida quantidade justifica a dificuldade em se detectar analiticamente este aminoácido.

TABELA 4. Composição em aminoácidos da fração protéica de tabletes de caldo de carne.

\begin{tabular}{lrrrr}
\hline \multirow{2}{*}{$\begin{array}{c}\text { Aminoácido } \\
\text { (aa) }\end{array}$} & $\mathrm{mg}$ aa/100g de amostra & \multicolumn{2}{c}{$\begin{array}{c}\mathrm{mg} \text { aa/tablete de caldo de carne } \\
(10,5 \mathrm{~g})\end{array}$} \\
\cline { 2 - 5 } & \multicolumn{1}{c}{$\mathrm{A}$} & $\mathrm{B}$ & $\mathrm{A}$ & $\mathrm{B}$ \\
\hline \hline Asp & $122 \pm 9$ & $117 \pm 13$ & $13 \pm 3$ & $19 \pm 1$ \\
Thr & $58 \pm 2$ & $59 \pm 4$ & $6 \pm 0$ & $6 \pm 1$ \\
Ser & $41 \pm 3$ & $63 \pm 3$ & $4 \pm 0$ & $7 \pm 0$ \\
Glu & $196 \pm 22$ & $163 \pm 11$ & $21 \pm 2$ & $17 \pm 1$ \\
Gly & $108 \pm 16$ & $138 \pm 50$ & $11 \pm 2$ & $15 \pm 1$ \\
Pro & nd & nd & nd & nd \\
Ala & $84 \pm 12$ & $78 \pm 8$ & $9 \pm 1$ & $8 \pm 1$ \\
Val & $56 \pm 5$ & $62 \pm 2$ & $6 \pm 0$ & $6 \pm 0$ \\
Met & nd & nd & nd & nd \\
lle & rraços & $32 \pm 1$ & troços & $3 \pm 0$ \\
Leu & $52 \pm 6$ & $58 \pm 4$ & $5 \pm 1$ & $6 \pm 0$ \\
Tyr & nd & nd & nd & nd \\
Phe & nd & nd & nd & nd \\
His & $69 \pm 7$ & $68+3$ & $7 \pm 1$ & $7 \pm 0$ \\
Lys & $62 \pm 6$ & $97 \pm 3$ & $6 \pm 2$ & $10 \pm 0$ \\
Trp & na & na & nd & nd \\
Arg & nd & nd & nd & nd \\
Total & $848 \pm 72$ & $996 \pm 29$ & $89 \pm 8$ & $105 \pm 3$ \\
\hline
\end{tabular}

(nd) não detectado

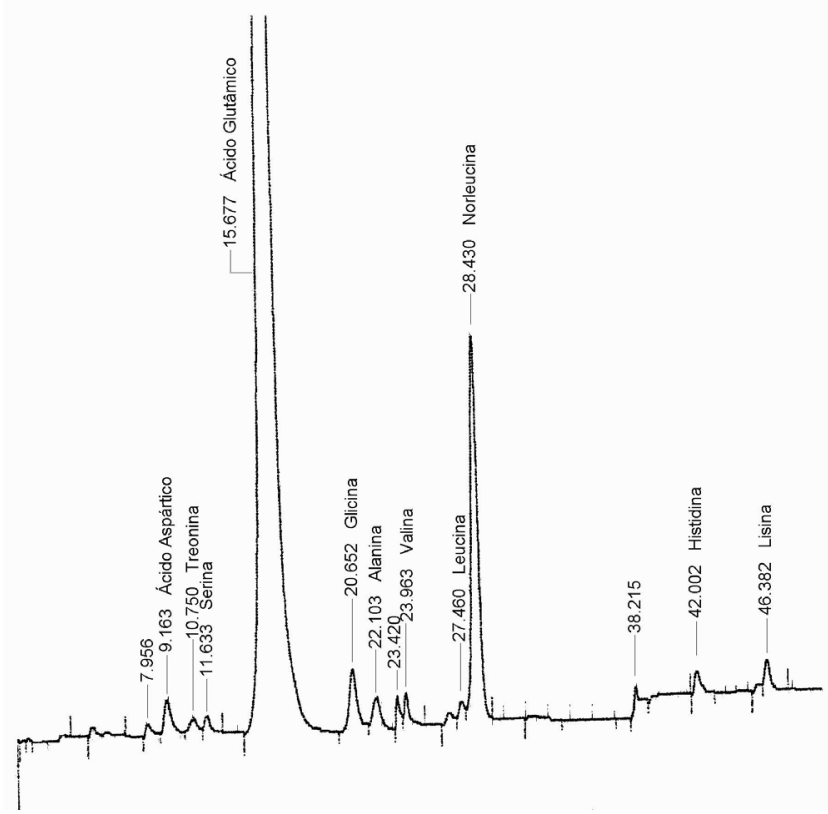

FIGURA 1. Aminograma representativo do extrato desengordurado para as duas marcas de tabletes de caldo de carne.

Na Figura 2 apresentamos o aminograma típico da fração protéica após precipitação com ácido acético 5,0\% (ou TCA 12,5\%), onde foi possivel observar os mesmos 
aminoácidos presentes na amostra integral. Já o aminograma da Figura 3 representa a fração não protéica dos tabletes de caldo de carne, sendo que o ácido glutâmico foi o único aminoácido encontrado, comprovando mais uma vez que o elevado teor de nitrogênio total corresponde, na maior parte, ao monoglutamato de sódio utilizado na formulação desses condimentos.

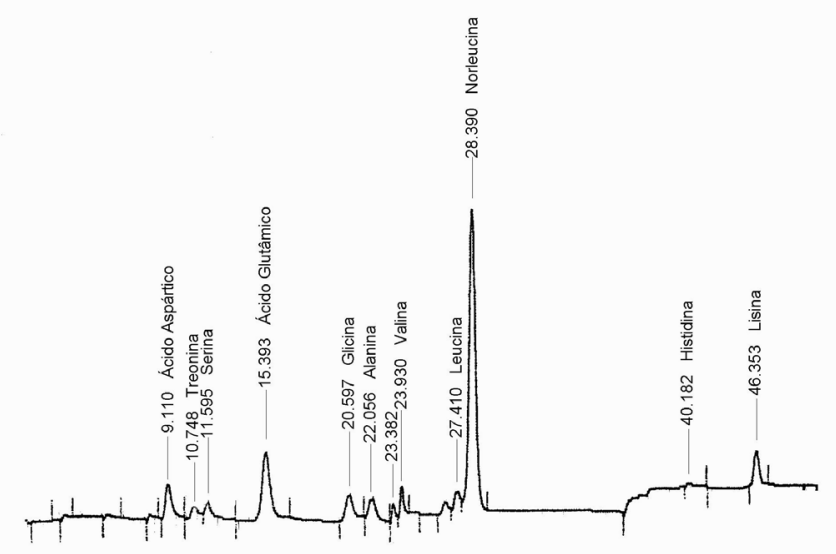

FIGURA 2. Aminograma representativo da fração protéica para as duas marcas de tabletes de caldo de carne.

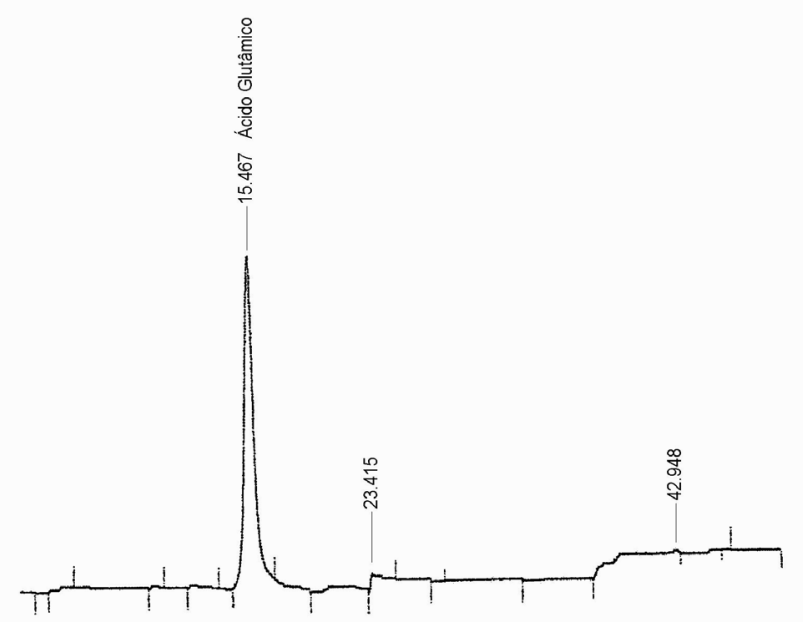

FIGURA 3. Aminograma representativo da fração não protéica para as duas marcas de tabletes de caldo de carne.

\section{4 - CONCLUSÕES}

O uso do fator de conversão de nitrogênio para proteína de 6,25 não foi adequado para estimar o teor protéico em duas amostras comerciais de "Tabletes de caldo de carne" porque estes produtos apresentam uma quantidade considerável de nitrogênio não protéico, na forma de monoglutamato de sódio, da ordem de 10 e $15 \%$, respectivamente. Os teores protéicos foram determinados após precipitação da proteína. Os valores en- contrados foram muito baixos, variando entre 0,44 a $0,52 \%$, quando determinados por $\mathrm{N} \mathrm{x} \mathrm{6,25,} \mathrm{e} \mathrm{de} \mathrm{0,72} \mathrm{a}$ $0,84 \%$, quando determinados pela somatória dos aminoácidos. Não foi possivel detectar a presença de Phe, embora, teoricamente, considerando que uma proteina contém $4 \%$ de Phe, os produtos possam conter $34 \mathrm{mg}$ Phe/100g de amostra. Os teores protéicos publicados em tabelas de composição de alimentos e declarados nos rótulos destes produtos provém da determinação de nitrogênio total multiplicado por 6,25 , portanto, superestimam a concentração protéica, e por conseguinte, o teor de fenilalanina. Os teores de umidade e de lipídeos foram semelhantes nos dois produtos com valores médios de 3,65 e 8,38\%. Os teores de fibra alimentar foram insignificantes, da ordem de $2 \%$ nos produtos. Vale ressaltar a elevada concentração de sais minerais, da ordem de $61 \%$ no produto A e de $54 \%$ no produto B.

\section{5 - REFERÊNCIAS BIBLIOGRÁFICAS}

[1] Acosta, P.B., ARnold, G., Berstein, L., Cho, S., GAFFIELD, B., KORSON, M., LESLIE, N., LEWIS, V., MARRIAGE, B., YANNICELLI, S., STEINER, R., PARTON P. Protein Status of Infants with Phenylketonuria Undergoing Nutrition Management. J. Am. Coll. Nutr., v. 18, n.2, p. 102-107, 1999.

[2] ACOSTA, P.B. \& ELSAS, L.J. Dietary management of inherited metabolic disease: phenylketonuria, galactosemia, tyrosinemia, homocystinuria maple syrup disease. ACELMU Publishers, Atlanta, Georgia, 1975.

[3] ASSOCIATION OF OFFICIAL ANALYTICAL CHEMISTS AOAC. Official methods of analysis. 16 ed. Arlington: AOAC, 1995, v. 1.

[4] ARBEITSGEMEINSCHAFT FÜR PÄDIATRISCHE DIÄTETIK. Nährwerttabelle. Münster: SHS, 1995. p.61. [Catálogo].

[5] BLACKBURN, S. Sample preparation and hydrolytic methods. In: Amino acid determination methods and techniques. New York: Marcel Vekkei Inc.,1978, p. 7-37.

[6] BRADFORD, M.M. A rapid and sensitive method for the quantitation of microgram quantities of protein utilizing the principle of protein dye-binding. Anal. Biochem., v. 72, p. 248-254, 1976.

[7] BREMER, H.J, ANNINOS, A., SCHULZ, B. Amino acid composition of food products used in the treatment of patients with disorders of the amino acid and protein metabolism. Eur. J. Pediatr., v. 155, suppl. 1, p.S108S114, 1996.

[8] CERone, R., SCHIAFFino, M.C., Di STEFAno, S., VENESELLI, E. Phenylketonuria: diet for life or not? Acta Paediatr., v. 88, p. 664-666, 1999.

[9] DANELL, E., EAKER, D. Amino acid and total protein content of the edible mushroom Cantharellus cibarius (Fries). J. Sci. Food Agric., v. 60, p. 333-337, 1992.

[10] FAO/WHO/UNU - Report of a Joint FAO/WHO/UNU Expert Consultation Energy and protein requirements. World Health Organisation Technical Report Series n. 724, Geneva, 1985.

[11] FITZGERALD, B., MORGAN, J., KEENE, N., ROLLINSON, R.,HODGSON, A., DALRYMPLE-SMITH,J. An investigation into diet treatment for adults with previously untreated phenylketonuria and severe intellectual disability. J. Intellect. Disability Res., v. 44, n. 1, p. 53-59, 2000. 
[12] FOLCH, J., LEE, M., SLOANNE, S.G.H. A simple method for the isolation and purification of total lipide from animal tissues. J. Biol. Chem., v. 226, p. 497-509, 1957.

[13] FREITAS, O., IZUMI, C., LARA, M.G., GREENE, L.J. New approaches to the treatment of phenylketonuria. Nutr. Rev., v. 57, n. 3, p. 65-70, 1999

[14] FUJIHARA, S., KATSUGA, A.,AOYAGI, Y., SUGAHARA, T. Nitrogen-to-protein conversion factors for some common edible mushrooms. J. Food Sci., v. 60, p. 1045-1047, 1995.

[15] GAINES, T.P. Determination of protein nitrogen in plants. J. AOAC Int., v. 60, n. 3, p. 590-593, 1977.

[16] HERnÁNDEZ, T. CENTENo, C. MARTÍNEZ, C., HERNÁNDEZ, A. Effect of solvent extraction on the nitrogen compounds in alfafa protein concentrate. $\mathbf{J}$. Agric. Food Chem., v. 43, p. 3065-3069, 1995.

[17] I.A.L. - Normas analíticas do Instituto Adolfo Lutz. 3.ed., São Paulo: Instituto Adolfo Lutz, 1985. 533p.(Volume 1, Métodos Químicos e Físicos para Análise de Alimentos).

[18] JONES, D.B. Factors for converting percentages of nitrogen in foods and feeds into percentages of protein. USDA Circ., v. 183, p. 1-21, 1931.

[19] KOCH, R., AZEN, C., FRIEDMAN, E.G., FISHLER, K., BAUMANN FRISCHILING, C., LIN, T. Care of the adult with phenylketonuria. Eur. J. Pediatr., v. 155, suppl. 1, p.S162-S164, 1996.

[20] LANFER MARQUEZ, U.M. \& PENTEADO, M. De V.C. Variação e nível de detalhamento de alguns nutrientes. Teor de fenilalanina. Bol. SBCTA, Campinas, v. 31, n. 2, p. 109-111, 1997.

[21] LOURENÇO, S.O., BARBARINO,E., LANFER MARQUEZ, U.M., AIDAR, E. Distribution of intracellular nitrogen in marine microalgae: basis for the calculation of specific nitrogen-to-protein conversion factors. J. Phycol., v. 34, n. 5, p. 798-811, 1998.

[22] LOWRY, O.H., ROSEBROUGH, N.J., FARR, A.L., RANDALL, R.L. Protein measurement with the Folin phenol reagent. J. Biol. Chem., v. 193, p. 265-275, 1951.

[23] LUCAS, B., GUERRERO, A., SIGAles, L., SOTELO, A. True protein content and non protein amino acid present in legumes seeds. Nutr. Rep. Int., v. 37, n. 3, p. 545-553, 1988.

[24] MIRA, N.V.M. de, MARQUEZ, U.M.L. Importância do diagnóstico e tratamento da fenilcetonúria. Revista de Saúde Pública, São Paulo, v. 34, n. 1, p. 86-95, 2000.
[25] NOLL, J. S.,SIMMONDS. D.H., BUSHUK.W. A modified biuret reagent for determination of protein. Cereal Chem., v. 51, p. 610-616, 1974.

[26] Phenylketonuria: Screening and Management. NIH Consensus Statement Online 2000 October 16-18, 17(3): 1-27. Acessado em Dezembro de 2001. Endereço eletrônico: http://odp.od.nih.gov/consensus/cons/113/ 113_intro.htm

[27] SALO-VAANANEN, P.P., KOIVISTOINEN, P.E. Determination of protein in foods: comparison of net protein and crude protein. Food Chem., v. 57, n. 1, p. 27-31, 1996.

[28] SCHUETT, V.E. Low protein list for PKU. Seattle: National PKU News, 1995. p. 156.

[29] SIMONNE, A.H. SIMONNE, E.H., EITENMILLER, R.R., MILLS, H.A, CRESMAN, C.P. Could the Dumas method replace The Kjeldahl digestion for nitrogen and protein determinations in foods? J. Sci. Food Agric., v. 73, n. 1, p. 39-45, 1997.

[30] SOSULSKI, F.W., IMAFIDON, G.I. Amino acid composition and nitrogen-to-protein conversion factors for animal and plant foods. J. Agric. Food Chem., v. 38, n. 1, p. 351356, 1990.

[31] souci, s.w., FAChMAnn, W., KRAuT, H. Food composition and nutrition tables. Stuttgart: Medpharm; Boca Raton: CRC, 2000. p. 1061.

[32] TOKORO, N., SAWADA, M., SUGANUMA, Y., MOCHIZUKI, M., MASUZAWA, K., AOYAMA, Y., ASHIDA, K. Nitrogen composition of vegetables common to Japan. J. Food Compos. Anal., v. 1, p. 18-25, 1987.

[33] WEGLAGE, J., FÜNDERS, B., ULLRICK, K., RUP, A., SCHMIDT, E. Psychosocial aspects in phenylketonuria. Eur. J. Pediatr., v. 155, suppl.1, p.S101-104, 1996.

[34] YEOH, H.-H., TRUONG, V.-D. Protein contents, amino acid compositions and nitrogen-to-protein conversion factors for Cassava roots. J. Sci. Food Agric., v. 70, p. 51-54, 1996.

\section{6 - AGRADECIMENTOS}

Os autores agradecem o apoio financeiro do Conselho Nacional de Desenvolvimento Científico e Tecnológico (CNPq) e a Inês Maria Henrique pelo auxílio técnico. 